\title{
The Actions of e-Branding and Content Marketing to Improve Consumer Relationships
}

\author{
Giuseppe Granata, PhD \\ Department of Economics and Law, \\ University of Cassino and Southern Lazio, Italy
}

Giancarlo Scozzese PhD

Department of Human and Social Sciences, University for Foreigners, Perugia, Italy

\begin{abstract}
The way of doing marketing has substantially changed in the digital age. This change represented the direct consequence of a technological revolution that has led to a radical change in the way in which consumers relate to products, companies and markets. Among the most evident manifestations of such process the figure of the cyber consumer emerges, which is characterized by the desire to express the uniqueness through the personalization of products or services one buys, the brands being uses and researched information. Even the prices are often established by the consumer, on the basis of the willingness to pay and the value he attributes to individual goods. The above-mentioned conditions have highlighted the inadequacy of traditional marketing methodologies, focused on the company rather than the consumer and voted for a generally unilateral communication, in responding effectively to these needs. Today, consumers want to maintain transparent relationships with companies through two-way communication, expertly nourished with information and entertainment content and open to external input.

The paper's goal is to discuss how internet-related tools can improve marketing content. What are the actions, to be put in place, to improve the marketing and communication in order to achieve a better relationship with the customer. Tools such as digital marketing, e-brand, storytelling, etc., are tools to improve relationships with customers by building a relationship that lasts over time.
\end{abstract}

Keywords: Content marketing, digital marketing, e-brand building, online branding, storytelling. 


\section{Introduction}

Content marketing is a strategy experimented by some pioneering companies such as Michelin and Coca Cola since the early 1900s. It is based on the creation and distribution of media content relevant to stakeholders and target consumers. It is aimed at increasing the company's audience and encouraging public approval to support its work, through contents of interest and quality.

With the digital revolution, consumers have moved to the web, where they are looking for ways to entertain, learn and communicate. At the same time, the media landscape has changed and users are demanding ever more multimedia, interactive and personalized content.

The so-called Millennials, children of the technological revolution started with the Internet, are consumers different from those of previous generations. They are wary of messages spread by traditional media and advertising, are always looking for new stimuli and consume large amounts of online content. In order to attract them and establish relationships with them, it is necessary to change sales strategies and adapt to the new rules of the game.

The renewed interest in content marketing in recent years is a response to changes in consumer habits resulting from the digital revolution.

The contents on the web are at the center of the functioning of search engines, whose algorithms have the purpose of separating those of high quality from those not relevant; they are also the key to stimulating participation and engagement on social media.

Content marketing and e-branding actions require companies to equip themselves with new professionals specialized in technologies, digital marketing, publishing and media in order to create relevant and stimulating content. In other words: appealing, relevant, shareable.

Because of what has been said so far, the analysis of the academic literature carried out is aimed at highlighting the factors that influence the success of a content marketing and e-branding strategy, which is crucial for the contents to play in the panorama of contemporary marketing. The relationships between content, engagement, trust and loyalty will be investigated to understand if and how these factors determine the construction of a solid e-brand.

The document is structured as follows: paragraph 1 provides a brief review of the literature regarding content marketing, paragraph 2 examines the main ways in which communication towards the consumer evolves. The following paragraphs analyze the tools that help to realize the content marketing strategies. Finally discussion and conclusion highlight some managerial implications and the final considerations on the subject. 


\section{The reference literature}

Content marketing is the business process that creates and distributes valuable content to attract, capture and engage a specific audience, in order to encourage the client to implement actions and profitable behavior for the company. This is a real and true strategy, which exploits different channels both online and offline to tell the story and the values of the company. Digital revolution is increasingly focusing on online channels, thus being able to benefit from budget and virility savings. The academic literature related to this topic is very limited, being a topic that, although not entirely new, is quite recent as regards its applications to the digital sphere. Thought leaders have, however, initiated an interesting literature addressed to marketing experts, full of case studies and examples to inspire and encourage the community to adopt this strategy in order to optimize digital marketing efforts. Content marketing is focused on creating a valuable experience.

At the base there is the desire to help consumers in their research, providing quality content that will help them to move towards the product or service that best matches their needs. The goal is to positively influence the opinion towards the company that offers the contents and, through the latter, position the business as a leader in its field. These contents are generally interesting, engaging, easy to share and functional, suggesting the consumer that the company producing them is also the owner of the product or service best suites them.

The perspective in which the content marketing operates is that to support the consumer aiming at producing contents related to the frequent doubts that beset users. In short, it seeks to respond to public demand both in terms of information and in terms of entertainment.

The main difference with other types of marketing is that this tends to conquer the so-called owned media instead of betting everything on paid media. Through the contents it optimizes the search strategy on search engines, giving impulse to the results of organic research. The basic assumption of content marketing is the awareness that the consumer is little interested in the company as such and takes at heart primarily his own needs and desires. To succeed in attracting such a disinterested public, companies must offer something that not only captures their attention, but one which helps them, entertains them, and surprises them.

Content marketing communicates with users and potential customers without trying to sell them anything. It is positioned among inbound marketing strategies, which tend not to interrupt the user's activities with advertising messages. On the contrary, it is the user who, by showing interest in a particular subject, searches for content related to this. If the content marketing strategy is well executed, the user will come across a content created by a company that, ideally, will answer exactly to his questions and, given the 
usefulness, will urge him to revisit the company website in the future, entering so in the marketing funnel.

Unlike what happens on social networks, where the contents are short and tend to be designed according to the nature of the social platform used, on the company blog it is better to use more extensive content such as blog posts or e-books enriched with infographics and more. Basically, if on social networks companies try to model their behavior based on that of users, on the corporate blog they behave similarly to media agencies.

In objective terms, what differentiates content marketing from social media marketing is that the former focuses on consumers' demand, while the latter is used to increase brand awareness, like for example generating conversations about the brand and customer retention, that is, customer support activities. However, social networks are an excellent channel to give visibility to the contents of the corporate blog.

The first study on content marketing dates back to 2014. It was conducted by Holliman and Rowley in the B2B field in order to identify characteristics and objectives, through qualitative research consisting of interviews addressed to managers coming from three countries and operating in five different sectors.

On this occasion one of the interviewees proposed a personal definition of content marketing: "Valuable, compelling and relevant content on a consistent basis to attract and retain customers through information that they actually want to receive".

Holliman's study highlights the common opinion of respondents according to the content marketing is a fundamental tool for increasing brand awareness, corporate credibility and consumer confidence in the brand.

\section{The new paradigm of communication with the consumer}

The change in purchasing habits and interaction with companies has led the latter to radically rethink their way of communicating with the consumer.

Digital marketing and e-branding in their various forms have transformed marketing departments, inducing companies to include new professional profiles and to change the planning and implementation mechanisms of preexisting strategies. The same role of marketing has changed. In fact, if before this tended to create consumers, today its purpose is to create passionate followers of the brand, who feel emotionally involved with the brand and feel pleasure and gratification in being part of a brand community. Content marketing has been used by companies for a long time; companies such as Michelin and P\&G started to create content as early as the beginning of the 20th century, and both the Michelin guide and the famous Soap Operas are considered the cult, the result of this marketing approach. However, it is only in recent times that a large-scale adoption has been recorded. 
The first of these is called acceptance. The contemporary consumer often informs himself through alternative and not necessarily official sources, looking for new perspectives on what is happening in the world.

The second barrier is made up of talent. Writers and journalists increasingly prefer to work in sectors not related to publishing, such as large companies or brands, and place their skills at the service of creating content.

Technological impediments constituted the third barrier. The technology available today allows anyone to create content with very low investment compared to the past.

According to what emerged from Holliman's study, content marketing induces companies to think in a more customer centric manner, resulting in a higher level of engagement and trust on the consumers' part, which consists of actions favorable to the company. Van Doorn et al. (2010) argue, in fact, that a greater level of customer engagement leads the user to interact and repeatedly manifest behaviors such as e-WOM and content sharing, which help to reinforce the positive image of the brand (Granata, 2016).

The conversations that are generated on the web as a consequence of these behaviors are mainly governed by the public, with little control by the companies. This aspect characterizes both social marketing media and content marketing. To capture the attention of today's public, demanding and accustomed in expressing their opinion about the companies' work and brands' values, companies act as media agencies. For the company acting like a media agency basically means telling the public its own story through contents that are able to emotionally involve users.

Consumers on the web have an unlimited amount of content and a short and fragmented concentration capacity. Above all the generation of those born after 1995, the so-called Gen. Z, has an attention span equal to only 8 seconds; from this it is deduced the importance for companies to propose relevant and compelling content.

Creating content of this type requires an investment of considerable resources for companies. According to Holloman et al. content should understand elements both static such as web pages, as well as dynamic, such as video, user-generated content, etc. Budikova (2014) noted that companies are inclined to use a variety of formats and channels to effectively communicate the brand and highlight to this context the key role played by the co-creation of content. He considers the latter as a fundamental asset to reinforce brand awareness amongst the public. The user-generated contents are in fact a source of inspiration with a marked authenticity thus providing a solution to the most typical problem posed by content marketing: the limited amount of business contents.

For the company, re-proposing user-generated content on its own channels "owned" enriches the offer with minimum effort, increases the credibility of 
the company, encourages the consolidation of the brand community and gives impulse to the sense of confidence felt by consumers for the brand. For the creation of videos, TV formats and digital assets, both talent and creativity as well as technical tools are necessary. Red Bull, Lego, Coca Cola, are among the companies from which an example is taken for content marketing. The first in particular boasts a Red Bull Media House responsible for creating branded content.

Another virtuous example in the wide goods consumption sector is Unilever, which with the establishment of U Studio, a department designed specifically for content marketing, has been moving part of the realization of assets internally. Even though the ways content created is similar in businesses and media agencies, the only difference we find is represented by the aim. For the former, the creation of content is in fact functional to the generation of income, for example through the sale of advertising space, while for the latter this is considered a way to attract potential customers and keep them faithful over time. In the first case, the content constitutes the founding principle of the business model, while in the latter supports the current business model.

\section{Objectives and metrics of content marketing: the content marketing funnel}

Sales funnel is defined as the purchasing process within which the customer is attracted and led by the company and which extends from the first contact with it until the conclusion of a real and proper purchase. This is historically the basis of the development of the corporate marketing strategy, but with the digital revolution it too has undergone changes.

The content marketing funnel consists in a re-visitation of the sales funnel in a perspective aligned with the needs of the market and contemporary consumers. Marketing experts today tend to support each phase of the funnel with unique and specially created content, which helps to attract, "nurture" and convert potential customers into paying customers and ultimately loyal customers. Pulizzi illustrates the individual phases of the funnel and uses them to explain some of the main business objectives that can be pursued through content marketing.

The first is the brand reinforcement phase: when a company approaches content marketing for the first time, the first objective that arises is a long-term strategy aimed at increasing brand awareness among the public, using alternative tools to advertising.

Lead conversion is the second phase and occurs when a user provides personal data and agrees that it can be used by the company for marketing initiatives. The so-called subscriptions are a classic example and allow the company to formulate offers and customized content for different groups of users, to be offered to them through a newsletter. 
Customer conversion is the phase on which marketing experts have always focused. It concerns the proof points that is the elements that induce the customer to conclude a purchase, because he is convinced that a certain product is better than the competing products.

The customer service phase adds value to the customer and reinforces the purchase decision after it has been concluded. The contents are an excellent tool to help customers get the best from the product purchased, increasing the shopping experience and the brand. An example is the FAQ section of corporate sites or chat bots for customer support, both aimed at providing answers to questions from customers who are using a given product or service.

Customer upsell is the post-sales phase that allows companies to continue communication with the customer in view of further future purchases. Holding a customer is less expensive than creating a new one and taking care of existing customers, proposing customized offers or additional products aligned to his interests, is a huge opportunity to increase sales.

The last stage of the funnel is that of the evangelists or advocates, that is of the brand's passionate clientele, and is the ultimate goal to which every company tends.

The contents generated by the customers are those that most support the growth of the business, because they are original and are among the most sought after and evaluated by other users. The loyal and passionate clientele gives life to communities, fan pages and relevant content about the brand. With the increasing participation of the consumer in the process of value creation, there is now a substantial transfer of power to the public, with the consequent co-creation of content through the dialogue between businesses and consumers on the web. This allows the company to effectively save substantial investments in resources to create business content. Content marketing is a complementary strategy to company marketing efforts and aims to improve results. Once the objectives have been set, it is necessary to identify how to act and what contents to develop. To this end we use the fill in the gaps technique; in a certain sector, as well as in a marketing strategy, there are always weaknesses to be identified

For example, these could be information that potential customers are looking for on the web whilst finding it difficult to locate, such as: differences between products, use, ingredients, contraindications, etc. These shortcomings are generally discovered through a search strategy that, by listening and monitoring the voice of consumers on the web, highlights the most frequently asked topics or questions that these search online for a given topic. The ultimate purpose of this is to suggest to the company topics to develop relevant content and consequently improve the company's website positioning in search engines. 
According to Rancati and Gordini (2014) the contents produced by the company must meet a series of requirements. In fact, it is expected that these:

- Generate interest and engagement, inform and educate the consumer.

- Express values that identify the company in terms of uniqueness, consistency, quality and relevance.

- Show a kind of pro-activity and ability to evolve over time.

The mentioned characteristics are ultimately necessary to create a multiplicity of contents aimed at providing a coherent image of the company and allow it to create added value for the consumer. The efficiency of content marketing can be monitored for Rancati through the metrics which is divided into four categories: consumption, sharing, lead generation and sales metrics. The consumption metrics help to measure the brand awareness and the traffic generated by the contents, thus allowing the satisfaction index to be checked. An example is the average time spent on the page and the number of visits to a page. This is very intuitive and easily obtainable data through free tools like Google Analytics. It is in the companies' interest that users not only regularly visit the company's website to make use of the contents, but also and above all that they share the contents they have created and disseminated through social channels, blogs and forums.

Content sharing metrics measure the level of content sharing by users, within their own contacts. This action has a direct impact on the level of audience engagement on the web. Likes, shares and links are indicators of the diffusion of a content within a wide network of users; however, they of content on the web is called e-WOM and the shareability is the aspect that makes certain content more suitable for online sharing in respect of others. Ho and Dempsey (2010) have conducted studies on personality traits, researching the motivations that lead users to share content on the web. Their theoretical model has analyzed three personal needs that are believed to push consumers towards this type of interpersonal communication: inclusion or need to belong to a group, affection or concern for others, control or desire to impose their individuality in a social context. While the first need turned out to be a not particularly relevant motivation, their research showed instead a positive relationship between individualism, altruism and sharing frequency. Sharing contents on the web reinforces the image of a user as an opinion leader, differentiates him from others and helps him in the development of his personal brand. In the same way the altruistic behavior, that is, interest towards the well-being of others, motivates him to share in view of his will so as to make the next well informed and satisfied.

Lead generation is that metric of content marketing that analyses the frequency with which the use of content results in a conversion. Depending on the product or service considered, this may emerge from the analysis of the 
number of downloads (for example in the case of an app), subscription to a newsletter, etc. It deals with a metric that, unlike those previously listed, gives an indication of the economic-financial value of content marketing.

Finally, sales metrics help identify the impact of content marketing on company performance and highlight its impact on the acquisition of new customers and sales targets. Examples of this are online and offline sales volumes, cost savings and customer retention.

Despite the importance of the mentioned metrics, it is still rather limited in use. This shows how content marketing is still seen in some contexts as a tool to publish and share content rather than a strategy to create value.

\section{Storytelling as a technique to narrate the values of the brand}

In addition to the already mentioned objectives, content marketing is aimed at sharing the splits of company life. Contents that show the life inside it, such as: employee testimonials, articles by the CEO and projects of social impact, get a much greater resonance among the general public, because they inspire a sense of authenticity and proximity to the consumer. Storytelling is the technique that companies use to tell their own story and as well that of their brands. The narration is a very old activity, which characterizes man and the understanding that he has of himself, of his environment and of the events that he lives.

Fog et al. (2005) explain how stories have always been part of our evolution as human beings. In a society that is increasingly driven by emotions, the need to tell and listen to stories is growing, therefore, it is no wonder that an ancient activity such as storytelling takes new forms, in our case, as a brand building tool.

The fragmentation of society we are currently experiencing and the lack of dominant authorities that impose values to which we must abide guarantee unprecedented freedom of choice. Individuals increasingly can choose what to believe in, what values to adopt and therefore surround themselves with symbols to communicate their lifestyle and personality. These symbols are often brands. According to Fog et al. the well-being of the industrialized countries satisfied the primary needs of individuals and led to an inverting of Maslow's pyramid.

People today focus on their personal fulfilment, on the development of their potential and the pursuit of their dreams. This phenomenon has made them less and less interested in the product itself, but extremely attracted to other elements such as: experiences, emotions, stories. Desirable products are those that appeal to the aspirations of individuals and are functional in communicating a point of view or lifestyle. The challenge for companies today is the creation of a brand that has solid values and for this purpose the technique of storytelling lends itself as a brand development tool. 
The stories told by the companies take hold of emotions, offer consumers something to believe in so much so that the purchased product becomes a means to tell the company's history. As already mentioned in the previous chapters, to obtain the loyalty of contemporary consumers it is necessary to create an experience that differentiates a brand from the competition. A story is by definition the narration of a series of connected events.

When we talk about the structure of the narration, we often refer to the actantial model formulated by the semiologist Greimas. This is considered a universally applicable generic model, which proposes a linear narrative structure according to the idea that written texts are governed by precise rules. In semiotic narrative, the narration is defined by the transformation that takes place between the initial and final moment of the story.

In Greimas's model he illustrates how the different historical actors conceive the world through narration; these are called actants and represent the structural units of the narration. The subject-actants, for example the characters of a story, interact with each other supporting the development of the plot, which usually consists of three forms of "proof" through which the subject undergoes transformation:

- épreuve qualifiante: it is the phase in which the subject obtains the skills to face the difficulties.

- épreuve principale: it is the stage of the fight or duel to obtain the object of desire.

- épreuve glorifiante: it is the phase in which the subject is confirmed as a "hero".

The Greimas model is used to understand the composition of a character and is often used in connection with the storytelling of various elements such as festivals, theme parks and video games. In each of these cases the individual acts as a hero in the world presented to him. This type of storytelling has received many criticisms in recent times, due to the fact that a linear model is considered too simple because it ignores the complexity of reality and therefore does not propose similar stories. In relation to the application of storytelling to brand management, the idea that companies must adopt a holistic approach has been increasingly imposed.

By holistic approach we mean the process of circulation of brand stories both inside and outside the company. In this way it is possible to create a socalled core or main story, made up of inputs proposed by consumers, employees and managers, able to better communicate the corporate culture and the values of the brand. The corporate identity inside and outside the company can thus become one whole, through a history in which all the stakeholders believe.

This idea of creating company history in a continuous way, welcoming contributions from different actors inside and outside the company, is linked 
to the concept of co-creation. Through co-creation there is a change of perspective: from the company's point of view as the main creator of value we move on to consider the consumer at the centre of this process.

Prahalad and Ramaswamy (2004), remember how historically the consumer was considered an actor outside the company's reality, involved only at the time of exchange. Today, however, these do not feel satisfied by the offer of products on the market and want to exert their influence at all stages of business processes. According to Prahalad et al. (2004) co-creation is closely linked to the consumer experience. These are the interactions between company and consumer that allow the co-creation of unique experiences, source of differentiation and competitive advantage: "Value is co-created at multiple points of interaction. Basis of value is co-creation experience".

The co-creation applied to storytelling has led to greater interaction between the narrator and the audience, creating a real dialogue. This approach is not only a source of benefits for the purposes of branding outside the company, but also at the organizational level. In fact, storytelling improves the processes of dissemination of knowledge and information whilst making sure that employees live the brand from within, assimilating and making its history their own.

Mangold et al. (2009) emphasize the importance of storytelling in the context of marketing communication aimed to the public outside the company; there is evidence of the effectiveness of this technique in terms of emotional engagement, information storage and sharing of content through word of mouth. This offers in fact numerous opportunities for co-creation that often encourage users to be more participative and to interact more often with the brand. In general, it has been noted that the more the consumer is involved in the process of co-creating satisfaction and loyalty to the company, the greater the likelihood that he will share the brand stories.

\section{Discussion}

We have seen how the Internet presents great opportunities for companies and their branding activities. In an electronic environment where the physical interaction with the client is greatly reduced and there is no possibility of verifying the quality of the products in first person, e-branding is of fundamental importance, because the reliance (trust) of the consumer towards the brand reduces the uncertainty and distrust, giving him back a sense of reliability and familiarity. The almost non-existent barriers to entry, the low cost in which the customer incurs when he buys a brand other than usual (switching cost) and the perception that he has of products as commodities are additional circumstances that bring out the e-brand as criterion of choice for the purchase of an asset. The business model on the web is very different 
compared to traditional models, as the division between company and customer is missing, as is the conceptual separation for the consumer between brand experience and brand. On the Internet these two components become in fact one and the experiential factor deeply influences the perception that the user has of the brand. Although some authors (Avlotinis G. J., Karayanni D. 2000) have attempted to identify the overall set of factors that determine the success of online branding, there is still a solid theoretical framework that considers the totality of the key elements.

According to a research carried out by Riyad et al. (2011) the branding on the web presents itself as a construction of relationships and alliances with customers, users and partner companies. This construction of relationships takes place through mechanisms that foster dialogue, the involvement of stakeholders in the process of value creation and word of mouth. These two elements allow the establishment of customer trust and e-loyalty, moreover that which companies tend through their e-branding strategies (Granata and Scozzese, 2017)

Reliance or trust generally precedes loyalty; its establishment is linked to the perception of security and reliability of the company or brand and has a direct impact on consumer's behavior during the online purchasing process. In a digital environment where the user has to rely on the information available on the web to find out about a product or service, the role played by the contents is fundamental to create and increase the sense of consumer confidence. Furthermore, studies have shown the positive relationship between the sense of security experienced by the consumer and the probability that these buy online at a specific website. Other factors that determine the level of trust on the part of the consumer are the privacy in terms of disclosure and use of personal data, the security of payment systems and the opinion of peers, transmitted through the e-WOM.

The e-WOM has emerged from the analysis of the academic literature as one of the elements that mostly determine the success of an e-branding strategy. This gives the users a sense of authenticity and determines both a greater openness of the companies towards the opinion of consumers, and an involvement of the latter in conversations with the company and regarding the brand. It is also functional to establish and consolidate brand communities. We have seen in this text work how much the relationship factor and the emotional bond between brand and consumer for loyalty purpose. Non-interaction with customers on a personal level, however, presents significant challenges to its establishment. Companies use alternative measures such as brand communities, co-creation of content and new buying experiences to encourage such a connection to differentiate themselves from the competition. In fact, they are created by the brand to serve users, but also co-created as a result of 
consumer interaction with the brand, where it is often a symbol of which the consumer uses to express his own individuality.

For Vinearean S. (2013), focusing on customer satisfaction is the best way for the brand to start an emotional relationship with the customer. A customer is satisfied when his overall evaluation of the experience with a brand and its products over time is positive. With this in mind, it is about the initial phase of the marketing funnel that marketing experts should pay more attention to. The stage of research and initial information exchange is in fact that in which the perceived value of the brand for the consumer plays a crucial role. A website that offers relevant content and a secure, intuitive and simple to use architecture will encourage the user to revisit the site and potentially repeat the purchase. A study conducted by Alavinasab and Kamal demonstrated the positive relationship between content quality and brand trust. The consumer has confidence in a brand that includes the pain points and provides solutions to alleviate them, assisting the user in reaching his goal, whatever it is. The set of factors mentioned above determines the brand experience, which is a function of both e-loyalty and brand equity.

\section{Conclusion}

The analysis carried out on the academic literature has highlighted how the quality of the content disclosed by a company, the way of interaction with users on the web (storytelling) and the co-creation have a direct impact both on users' trust towards the brand, that on their overall experience and the construction of e-loyalty. This translates into the construction of a strong relationship between business and consumer that makes the relationship solid and lasting. It is suggested that companies consider the possibility of starting to shift the focus from within their company to a more communicative and open to the public.

In a technological environment made up of dialogue, it is considered essential to start co-creation processes with users and to direct the purpose of company activities towards a continuous service to the customer and a personalization of the offer; in both these areas the content marketing can be of great support to the achievement of the business objectives.

Finally, the awareness that on the web the brand experience is considered one with the brand can help companies to understand the strategic importance of a superior brand experience, encouraging companies to invest more resources in activities aimed at improving this aspect, crucial to a successful e-branding process.

Therefore, combining traditional marketing and communication techniques and projecting towards the digital world, allows us to achieve goals of relations with consumers in a faster, more incisive and stronger way. It 
improves the relationship with the consumer and the company draws from it more and more useful information for future strategies.

In conclusion, the analysis carried out on the academic literature highlighted how the quality of the contents disclosed by a company, the way in which users interact on the web (storytelling) and the co-creation have a direct impact both on users' trust towards the brand, which on their overall experience and the construction of e-loyalty.

These conclusions respond positively to the objectives of the paper on the elements of reflection for possible managerial implications.

It is suggested that companies consider the possibility of starting to shift the focus from within their company to a more communicative and open to the public.

In a technological environment made up of dialogue, it is considered essential to start co-creation processes with users and to direct the purpose of company activities towards a continuous service to the customer and a personalization of the offer; in both these areas the content marketing can be of great support to the achievement of the business objectives.

Finally, the awareness that on the web the brand experience is considered one with the brand can help companies to understand the strategic importance of a superior brand experience, encouraging companies to invest more resources in activities aimed at improving this aspect. crucial to a successful e-branding process.

\section{References:}

1. Alavinasab S. M., Kamal S. H., (2015) Studying the Influencing Factors on Online Brand Trust, International Journal of Economy, Management and Social Sciences, Vol. 4, N. 1, January 2015.

2. Avlotinis G. J., Karayanni D., (2000), The Impact of Internet Use on Business-to Business Marketing: Examples from American and European Companies, Industrial Marketing Management 29, 441459, Elsevier Science Inc.

3. Belanger F., Hiller J., Smith W., (2002), Trustworthiness in electronic commerce: the role of privacy, security, and site attributes, Journal of Strategic Information Systems 11, 245-270, Elsevier.

4. Budikova J., (2014), How digital trends are changing the marketing landscape, Central European Business Review, Vol. 3 N. 2, June.

5. Fog K., Budtz C., Yakaboylu B., (2005), Storytelling: Branding in practice, Springer-Verlag Berlin Heidelberg.

6. Granata, G., (2016), Business Communication 2.0, Aracne editor.

7. Granata, G., \& Scozzeze G., (2017), The Influence of Virtual Communities in Marketing Decision in International Business 
$\begin{array}{llllll}\text { Research, } & \text { Vol. } & 10 & \mathrm{n}^{\circ} & 12, & \text { ISSN }\end{array}$ doi:10.5539/ibrv10n12p191.

8. Gunelius, S., (2011), Content Marketing for Dummies. Wiley: New York, 2011.

9. Ho J. Y., Dempsey M., (2010) Viral marketing: Motivations to forward online content, Journal of Business Research, 63(9), 1000-1006.

10. Holliman G., Rowley J., (2014), Business to business digital content marketing: marketers' perceptions of best practice, Journal of research in interactive marketing, 8(4), pp. 269-293.

11. Kim J. H., Hong J. H., (2014), Designing Urban Media Storytelling through Greimas' narrative Model, International Journal of Multimedia and Ubiquitous Engineering, Vol. 9 N. 3, pp. 393-402.

12. Lieb, R., (2011), Content Marketing: think like a publisher. How to use content to market online and in social media. Que Publishing: Indianapolis.

13. market online and in social media. Que Publishing: Indianapolis, 2011.

14. Mangold W. G., Faulds, D. J., (2009), Social media: The new hybrid element of the promotion mix, Business horizons 52 pp. 357-365.

15. Parkin, G., (2009), Digital Marketing. Strategies for online success. New Holland Publishers: London.

16. Prahalad C. K., Ramaswamy V., (2004), Co-creation experiences: The next practice in value creation, Journal of Interactive Marketing, Harvard Business School Press, pp. 5-14.

17. Pulizzi J., Rose R., (2011), Managing Content Marketing, CMI Books of Z Squared Media, Cleveland Ohio.

18. Pulizzi J., (2014), Epic content marketing, Mac Graw-Hill education.

19. Rancati E., Gordini N.,(2014), Content Marketing Metrics: Theoretical Aspects and Empirical Evidence, European Scientific Journal, edition vol.10, No.34.

20. Riyad E., Al Sharief R., Hussein L., (2011), Factors Affecting the Success of Online Branding: An Empirical Study, International Journal of Online Marketing, 1(4), 20-32, October-December.

21. Van Doorn J., Lemon K., Mittal V., Nass S., Pick D., Pirner P., Verhoef P., (2010), Customer Engagement Behaviour: Theoretical Foundations and Research Directions, Journal of Service Research.

22. Vinerean S., (2013), The Impact of Customer Perceptions and Satisfaction on E-Loyalty, Expert Journal of Marketing, 1, 4-16. 